\title{
流体構造連成の整合プロジェクション解法*
}

\author{
石原 大輔*1, 堀江 知義 ${ }^{* 1}$
}

\section{Consistent Projection Method for Fluid-Structure Interaction}

\author{
Daisuke ISHIHARA ${ }^{* 1}$ and Tomoyoshi HORIE \\ ${ }^{* 1}$ Kyushu Institute of Technology, Department of Mechanical Information Science and Technology \\ 680-4 Kawazu, Iizuka, Fukuoka 820-8502, Japan
}

In this study a consistent projection method for the fluid-structure interaction (FSI) was proposed. The intermediate state variables were used to split the monolithic equation system into the equilibrium equations and the pressure Poisson equation (PPE). The incompressibility constraint is asymptotically satisfied by solving the proposed PPE in the iterative solution procedure under the asymptotic agreement of the intermediate velocity with the velocity. Therefore the proposed method is consistent with the monolithic method. The performance of the present method was demonstrated using a channel, which is one of typical test problems, and a flexible wing flapping in the closed fluid domain with the comparable fluid and structural densities.

Key Words : Incompressible Fluid, Monolithic Method, Projection Method, Fluid-Structure Interaction, Splitting

\section{1. 緒言}

流体構造連成（Fluid-Structure Interaction；FSI）には，しばしば強い非線形性や動力学的相似モデリングの困難 さ(1)があるので，それに対する理論・実験的アプローチが困難な場合がある.ゆえにその研究において計算力学 が有効であるフプロジェクション解法（projection method） ${ }^{(2)}$ は，その計算効率の良さから，非圧縮性流体解析に おいて成功をおさめている(3). ゆえにこのタイプの解法が流体の非圧縮性を含む FSI 解析に対して有効であるこ とが期待される. 実際, FSI のプロジェクション解法がいくつか提案されており, 偏微分方程式レベルでの分割 (splitting) に基づく解法 ${ }^{(4)}$ ，ブロック LU 分解（block-LU factorization）による離散化方程式レベルでの分割（以 下，代数的分割（algebraic splitting）と呼ぶ）に基づく解法(5)，またはサブストラクチャリング (substructuring) による代数的分割に基づく解法(7)(8)のいずれかに分類できる．一般に，FSI 解法の定式化における代数的分割は， 負荷の高い計算を伴う。そして計算効率のためにそれを近似することが計算の頑健性を損なう可能性がある (8)(9)(10)ことを念頭に置く必要がある.

本研究で提案するプロジェクション解法では，上述の代数的分割と異なり，FSI の一体型方程式を平衡方程式 と圧力ポアソン方程式 (pressure Poisson equation; PPE) に，中間状態変数を用いて分割する. FSI におけるこのタ イプの分割は，最初に文献（11）において，非圧縮性流体と剛体の連成に対して提案され，文献（12）において， 線形弾性体への拡張について述べられている. 本研究では, 非線形方程式の反復解法の枠組みの中で, 中間状態 変数による代数的分割を行う。この結果, 一体型解法との整合性を保ちつつ, 方程式の自由度を低減できる. こ の整合性は, 反復計算の中で, 中間速度と速度が漸近的に一致するならば，本 PPE を解くことにより，流体の非 圧縮性条件が漸近的に満たされることによる.

流路中に設置された柔軟な弁の問題 ${ }^{(6)}$ と薄く柔軟な弾性翼がそれと同程度の質量密度を持つ流体で満たされた 閉領域内で羽ばたく問題において，本プロジェクション解法の性能を実証する. 前者は典型的なテスト問題のひ とつである. 分離型解法をこれらの問題に適用した場合, 連成反復が収束しにくい，あるいは収束しないといっ

\footnotetext{
* 原稿受付 2012 年 11 月 2 日

*1 正員, 九州工業大学 (下820-8502 福岡県飯塚市川津 680-4)

E-mail: ishihara@mse.kyutech.ac.jp
} 
た数值的困難さが生じる ${ }^{(13)(14)(15)}$ ．本解法はこれらの問題を安定に精度良く解析できることが示される.

\section{2. 整合プロジェクション解法}

\section{$2 \cdot 1$ 支配方程式}

$\Omega_{t}^{\mathrm{f}}$ と $\Omega_{t}^{\mathrm{s}}$ はそれぞれ時間 $t$ における流体と弾性構造の領域, $\Gamma^{\mathrm{fs}}{ }_{t}$ は $t$ における流体構造境界を表す．ここで上付 き添え字 $\mathrm{f} ， \mathrm{~s}$ および fs はそれぞれ流体，構造および流体構造境界に関する量であることを表す．以下では，直交 座標系を用いる. ALE (Arbitrary Lagrangian-Eulerian) 法 ${ }^{(19)}$ を用いて, 移動境界を有する領域内の流体運動を記 述する．このとき非圧縮性ナビエ - ストークス方程式は，次のように表すことができる：

$$
\rho^{\mathrm{f}} \frac{\partial v^{\mathrm{f}}{ }_{i}}{\partial t}+\rho^{\mathrm{f}}\left(v^{\mathrm{f}}{ }_{j}-v^{\mathrm{m}}{ }_{j}\right) \frac{\partial v^{\mathrm{f}}{ }_{i}}{\partial x_{j}}=\frac{\partial \sigma^{\mathrm{f}}{ }_{j i}}{\partial x_{j}}+\rho^{\mathrm{f}} g^{\mathrm{f}}{ }_{i} \quad \text { and } \quad \frac{\partial v^{\mathrm{f}}{ }_{i}}{\partial x_{i}}=0 \quad \text { in } \Omega_{t}^{\mathrm{f}}
$$

ここで $\rho$ は質量密度, $v_{i}$ は速度ベクトルの第 $i$ 成分, $v^{\mathrm{m}}{ }_{i}$ は ALE 座標の速度ベクトルの第 $i$ 成分, $\sigma_{i j}$ はコーシー応 カテンソルの $i j$ 成分, $g_{i}$ は体積力ベクトルの第 $i$ 成分を表す. 流体はニュートン流体であると仮定する.

弾性構造の平衡方程式は，次のように表すことができる：

$$
\rho^{\mathrm{s}} \frac{\mathrm{d}^{2} u_{i}^{\mathrm{s}}}{\mathrm{d} t^{2}}=\frac{\partial \sigma_{j i}^{\mathrm{s}}}{\partial x_{j}}+\rho^{\mathrm{s}} g^{\mathrm{s}}{ }_{i} \quad \text { in } \Omega_{t}^{\mathrm{s}}
$$

ここで $u_{i}$ は変位ベクトルの第 $i$ 成分を表す，構造は有限変形するが，そのひずみは小さいものとして，線形弾性 材料であると仮定する.

次の幾何学的適合条件と平衡条件（境界面条件）が流体構造境界面に課される：

$$
v^{\mathrm{f}}{ }_{i}=v_{i}^{\mathrm{s}} \text { and } \sigma_{i j}^{f} n_{j}^{f}+\sigma_{i j}^{s} n_{j}^{s}=0 \text { on } \Gamma^{\mathrm{fs}}{ }_{t}
$$

ここで $n_{i}$ は流体または構造に対する外向き法線べクトルを表す.

\section{$2 \cdot 2$ 一体型方程式}

式 (1), (2) の有限要素離散化を行う。ここで構造の幾何学的非線形性に対応するために, total Lagrange 法を 用いる. 式 (3) を用いて, 流体と構造の離散化方程式を 1 つにまとめると, 次の一体型方程式を得る ${ }^{(16)}$ :

$$
{ }_{\mathrm{L}} \mathbf{M a}+\mathbf{C v}+\mathbf{N}+\mathbf{q}(\mathbf{u})-\mathbf{G p}=\mathbf{g} \text { and }{ }_{\tau} \mathbf{G v}=\mathbf{0}
$$

ここで，これらの式に表れる行列は，次のように定義される：

$$
{ }_{\mathrm{L}} \mathbf{M} \equiv\left[\begin{array}{ccc}
{ }_{\mathrm{L}} \mathbf{M}^{\mathrm{f}}{ }_{i i} & \mathbf{0} & \mathbf{0} \\
\mathbf{0} & { }_{\mathrm{L}} \mathbf{M}^{\mathrm{fs}}{ }_{c c} & \mathbf{0} \\
\mathbf{0} & \mathbf{0} & { }_{\mathrm{L}} \mathbf{M}^{\mathrm{s}}{ }_{i i}
\end{array}\right], \quad \mathbf{C} \equiv\left[\begin{array}{ccc}
\mathbf{C}^{\mathrm{f}}{ }_{i i} & \mathbf{C}^{\mathrm{f}}{ }_{i c} & \mathbf{0} \\
\mathbf{C}^{\mathrm{f}}{ }_{c i} & \mathbf{C}^{\mathrm{f}}{ }_{c c} & \mathbf{0} \\
\mathbf{0} & \mathbf{0} & \mathbf{0}
\end{array}\right], \quad \mathbf{G} \equiv\left[\begin{array}{c}
\mathbf{G}^{\mathrm{f}}{ }_{i} \\
\mathbf{G}^{\mathrm{f}}{ }_{c} \\
\mathbf{0}
\end{array}\right], \quad \mathbf{N} \equiv\left\{\begin{array}{c}
\mathbf{N}^{\mathrm{f}}{ }_{i} \\
\mathbf{N}^{\mathrm{f}}{ }_{c} \\
\mathbf{0}
\end{array}\right\}
$$


$\mathbf{q}(\mathbf{u}) \equiv\left\{\begin{array}{c}\mathbf{0} \\ \mathbf{q}^{\mathrm{s}}{ }_{c}\left(\mathbf{u}^{\mathrm{s}}\right) \\ \mathbf{q}^{\mathrm{s}}{ }_{i}\left(\mathbf{u}^{\mathrm{s}}\right)\end{array}\right\}, \quad \mathbf{g} \equiv\left\{\begin{array}{c}\mathbf{g}^{\mathrm{f}}{ }_{i} \\ \mathbf{g}^{\mathrm{fs}}{ }_{c} \\ \mathbf{g}^{\mathrm{s}}{ }_{i}\end{array}\right\}, \quad \mathbf{a} \equiv\left\{\begin{array}{c}\mathbf{a}^{\mathrm{f}}{ }_{i} \\ \mathbf{a}^{\mathrm{fs}_{\mathrm{s}}}{ }_{c} \\ \mathbf{a}^{\mathrm{s}}{ }_{i}\end{array}\right\}, \quad \mathbf{v} \equiv\left\{\begin{array}{c}\mathbf{v}^{\mathrm{f}}{ }_{i} \\ \mathbf{v}^{\mathrm{fs}}{ }_{c} \\ \mathbf{v}^{\mathrm{s}}{ }_{i}\end{array}\right\}, \quad \mathbf{u} \equiv\left\{\begin{array}{c}* \\ \mathbf{u}^{\mathrm{fs}_{c}}{ }_{c} \\ \mathbf{u}^{\mathrm{s}}{ }_{i}\end{array}\right\}, \quad \mathbf{p} \equiv \mathbf{p}^{\mathrm{f}}$

${ }_{\mathrm{L}} \mathbf{M}_{c c}^{\mathrm{fs}} \equiv_{\mathrm{L}} \mathbf{M}_{c c}^{\mathrm{f}}+{ }_{\mathrm{L}} \mathbf{M}_{c c}^{\mathrm{s}}$

ここで， $\mathbf{M}$ は質量行列， $\mathbf{C}$ は拡散行列， $\mathbf{N}$ は移流項ベクトル， $\mathbf{G}$ は発散行列， $\mathbf{q}$ は弾性内力ベクトル， $\mathbf{g}$ は外力 ベクトル, $\mathbf{a}$ は加速度ベクトル, $\mathbf{v}$ は速度ベクトル, $\mathbf{u}$ は変位ベクトル, $\mathbf{p}$ は圧力ベクトル, 下付き添え字 $i$ と はそれぞれ非連成と連成自由度，下付き添え字 L は行列の対角集中化，下付き添え字 $\tau$ は行列の転置を表寸. 質 量行列の対角集中化の方法はいくつかあるが, 本研究においては, 要素の質量を節点に等分配する方法を用いた.

\section{$2 \cdot 3$ 本プロジェクション解法の定式化}

前反復 $k-1$ から現反復 $k$ への状態変数の増分を次のように定義する :

$$
\begin{aligned}
{ }^{t+\Delta t} \mathbf{a}^{(k)} & ={ }^{t+\Delta t} \mathbf{a}^{(k-1)}+\Delta \mathbf{a} \\
{ }^{t+\Delta t} \mathbf{v}^{(k)} & ={ }^{t+\Delta t} \mathbf{v}^{(k-1)}+\Delta \mathbf{v}={ }^{t+\Delta t} \mathbf{v}^{(k-1)}+\gamma \Delta t \Delta \mathbf{a} \\
{ }^{t+\Delta t} \mathbf{u}^{(k)} & ={ }^{t+\Delta t} \mathbf{u}^{(k-1)}+\Delta \mathbf{u}={ }^{t+\Delta t} \mathbf{u}^{(k-1)}+\beta \Delta t^{2} \Delta \mathbf{a} \\
{ }^{t+\Delta t} \mathbf{p}^{(k)} & ={ }^{t+\Delta t} \mathbf{p}^{(k-1)}+\Delta \mathbf{p}
\end{aligned}
$$

ここで, ${ }^{t+\Delta t} \mathbf{a}^{(k)},{ }^{t+\Delta t} \mathbf{v}^{(k)},{ }^{t+\Delta t} \mathbf{u}^{(k)},{ }^{t+\Delta t} \mathbf{p}^{(k)}$ はそれぞれ現時刻 $t+\Delta t$ の反復 $k$ における加速度, 速度, 変位, 圧力を表し, $\Delta \mathbf{a}, \Delta \mathbf{v}, \Delta \mathbf{u}, \Delta \mathbf{p}$ はそれぞれ加速度増分, 速度増分, 変位増分, 圧力増分を表す. 上式において, ニューマーク $\beta$ 法に基づく増分間の関係式（ $\left(\Delta \mathbf{u}=\beta \Delta t^{2} \Delta \mathbf{a}, \Delta \mathbf{v}=\gamma \Delta t \Delta \mathbf{a}\right)$ を適用している．式（6）を用いて，平衡方程式（4a） を線形化すると次式が得られる：

$$
{ }^{t+\Delta t} \mathbf{M}^{*(k-1)} \Delta \mathbf{a}-\mathbf{G} \Delta \mathbf{p}=\Delta \mathbf{g}
$$

ここで式 (4a) の圧力・弾性内力項を未知の状態変数を用いて陰的に評価した. 上式において, 残差力 $\Delta \mathbf{g}$ は次 のように定義される：

$$
\Delta \mathbf{g} \equiv{ }^{t+\Delta t} \mathbf{g}-\left({ }_{\mathrm{L}} \mathbf{M}^{t+\Delta t} \mathbf{a}^{(k-1)}+\mathbf{C}^{t+\Delta t} \mathbf{v}^{(k-1)}+{ }^{t+\Delta t} \mathbf{N}^{(k-1)}+\mathbf{q}\left({ }^{t+\Delta t} \mathbf{u}^{(k-1)}\right)-\mathbf{G}^{t+\Delta t} \mathbf{p}^{(k-1)}\right)
$$

また式（7）において， M*は一般化質量行列であり，流体の移流・拡散項の評価方法に応じて変わる. 本研究に

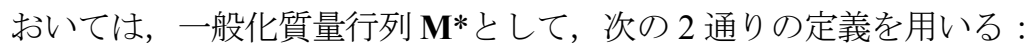

（定義 1）流体の移流項を陽的に評価し，流体の拡散項を陰的に評価する場合，

$$
\mathbf{M}^{*} \equiv_{\mathbf{L}} \mathbf{M}+\gamma \Delta t \mathbf{C}+\beta \Delta t^{2} \mathbf{K}
$$

と与えられる.ここで行列 $\mathbf{K}$ は弾性内力ベクトル $\mathbf{q}^{\mathrm{s}}$ のヤコビ行列である構造接線行列 $\mathbf{K}^{\mathrm{s}}$ を用いて次のように定 義される： 


$$
\mathbf{K}=\left[\begin{array}{ccc}
\mathbf{0} & \mathbf{0} & \mathbf{0} \\
\mathbf{0} & \mathbf{K}^{\mathrm{s}} & \mathbf{K}^{\mathrm{s}}{ }_{c i} \\
\mathbf{0} & \mathbf{K}^{\mathrm{s}} & \mathbf{K}^{\mathrm{s}}{ }_{i i}
\end{array}\right]
$$

（定義 2）流体の移流・拡散項を陽的に評価する場合,

$$
\mathbf{M}^{*} \equiv_{\mathrm{L}} \mathbf{M}+\beta \Delta t^{2} \mathbf{K}
$$

\section{と与えられる.}

時間進行における時間増分 $\Delta t$ に対寸る必要条件として, 定義 1 の場合, 次のクーラン数条件, 定義 2 の場合, それに加えて, 次の拡散数条件が課せられる：

Courant's number condition $V^{\mathrm{f}} \Delta t / \Delta h^{\mathrm{f}}<1$ and diffusion number condition $\left(\mu^{\mathrm{f}} / \rho^{\mathrm{f}}\right) \Delta t / \Delta h^{\mathrm{f} 2}<1 / 2$

$(12 \mathrm{a}, \mathrm{b})$

ここで $V^{\mathrm{f}}$ は代表流速, $\Delta h^{\mathrm{f}}$ は流体要素の最小寸法, $\mu^{\mathrm{f}}$ は流体の粘性係数を表す.

状態変数の予測である中間状態変数 ${ }^{t+\Delta t} \hat{\mathbf{a}}^{(k)},{ }^{t+\Delta t} \hat{\mathbf{v}}^{(k)},{ }^{t+\Delta t} \hat{\mathbf{u}}^{(k)}$ を得るために, 平衡方程式（4a）において，圧力

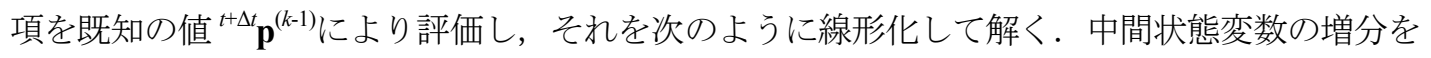

$$
\begin{aligned}
& { }^{t+\Delta t} \hat{\mathbf{a}}^{(k)}={ }^{t+\Delta t} \mathbf{a}^{(k-1)}+\Delta \hat{\mathbf{a}} \\
& { }^{t+\Delta t} \hat{\mathbf{v}}^{(k)}={ }^{t+\Delta t} \mathbf{v}^{(k-1)}+\gamma \Delta t \Delta \hat{\mathbf{a}} \\
& { }^{t+\Delta t} \hat{\mathbf{u}}{ }^{(k)}={ }^{t+\Delta t} \mathbf{u}^{(k-1)}+\beta \Delta t^{2} \Delta \hat{\mathbf{a}}
\end{aligned}
$$

と定義し, 前反復で求めた既知の圧力 ${ }^{t+\Delta t} \mathbf{p}^{(k-1)}$ を用いた平衡方程式（4a) を線形化すると次式が得られる：

$$
{ }^{t+\Delta t} \mathbf{M}^{*(k-1)} \Delta \hat{\mathbf{a}}=\Delta \mathbf{g}
$$

ここで $\Delta \hat{\mathbf{a}}$ は中間加速度の増分を表す.

式（7）と式（14）の差に，式（6b）と式（13b）を適用すると次式を得る：

$$
\gamma \Delta t \mathbf{G} \Delta \mathbf{p}={ }^{t+\Delta t} \mathbf{M}^{*(k-1)}\left({ }^{t+\Delta t} \mathbf{v}^{(k)}-{ }^{t+\Delta t} \hat{\mathbf{v}}^{(k)}\right)
$$

この両辺に左から ${ }_{\tau} \mathbf{G}_{\mathrm{L}} \mathbf{M}^{-1}$ を乗じ，式（9）あるいは式（11）を用いると次式を得る：

$$
\gamma \Delta t_{\tau} \mathbf{G}_{\mathrm{L}} \mathbf{M}^{-1} \mathbf{G} \Delta \mathbf{p}={ }_{\tau} \mathbf{G}^{t+\Delta t} \mathbf{v}^{(k)}-{ }_{\tau} \mathbf{G}^{t+\Delta t} \hat{\mathbf{v}}^{(k)}+{ }_{\tau} \mathbf{G}_{\mathrm{L}} \mathbf{M}^{-1 t+\Delta t} \overline{\mathbf{M}}^{*(k-1)}\left({ }^{t+\Delta t} \mathbf{v}^{(k)}-^{t+\Delta t} \hat{\mathbf{v}}^{(k)}\right)
$$

ここで行列 $\overline{\mathbf{M}}^{*}$ は次式により定義される：

$$
\overline{\mathbf{M}}^{*} \equiv \mathbf{M}^{*}{ }_{\mathrm{L}} \mathbf{M}
$$

ここで次の PPE を解くことにより, 未知の流速場に対する非圧縮性条件 (4b) が漸近的に満足されることを示す： 


$$
\gamma \Delta t_{\tau} \mathbf{G}_{\mathrm{L}} \mathbf{M}^{-1} \mathbf{G} \Delta \mathbf{p}=-{ }_{\tau} \mathbf{G}^{t+\Delta t} \hat{\mathbf{v}}^{(k)}
$$

PPE（18）を解くとき，式（16）は，

$$
{ }_{\tau} \mathbf{G}^{t+\Delta t} \mathbf{v}^{(k)}+{ }_{\tau} \mathbf{G}_{\mathrm{L}} \mathbf{M}^{-1 t+\Delta t} \overline{\mathbf{M}}^{*(k-1)}\left({ }^{t+\Delta t} \mathbf{v}^{(k)}-{ }^{t+\Delta t} \hat{\mathbf{v}}^{(k)}\right)=\mathbf{0}
$$

となる.ゆえに反復計算により，

$$
\left|{ }^{t+\Delta t} \mathbf{v}^{(k)}-{ }^{t+\Delta t} \hat{\mathbf{v}}^{(k)}\right| \rightarrow 0
$$

となるならば，上式左辺第 2 項が 0 になり，未知の流速場に対する非圧縮性条件（4b）が漸近的に満たされる. 本プロジェクション解法は次のようにまとめられる：

Step1 : 式（14）を解くことにより, 中間加速度 $\Delta \hat{\mathbf{a}}$ が求まり, それから式（13b）を用いて, 中間速度 ${ }^{t+\Delta t} \hat{\mathbf{v}}^{(k)}$ が 求まる.

Step2：式（18）を解くことにより，圧力増分 $\Delta \mathbf{p}$ が求まる.

Step3 : 式 (7) を解くことにより, 加速度増分 $\Delta \mathbf{a}$ が求まり, それから式 (6) を用いて, 加速度 ${ }^{t+\Delta t} \mathbf{a}^{(k)}$, 速度 ${ }^{t+\Delta t} \mathbf{v}^{(k)}$, 変位 ${ }^{t+\Delta t} \mathbf{u}^{(k)}$ が求まる.

定義 2 の式（11）を用いる場合，式（14）は次のように流体の非連成自由度とそれ以外の自由度に分離できる：

$$
\begin{aligned}
& { }_{\mathrm{L}} \mathbf{M}^{\mathrm{f}}{ }_{i i} \Delta \hat{\mathbf{a}}^{\mathrm{f}}{ }_{i}=\Delta \mathbf{g}^{\mathrm{f}}{ }_{i} \\
& {\left[\begin{array}{cc}
{ }_{\mathrm{L}} \mathbf{M}^{\mathrm{fs}}{ }_{c c}+\beta \Delta t^{2} \mathbf{K}^{\mathrm{s}}{ }_{c c} & \beta \Delta t^{2} \mathbf{K}^{\mathrm{s}}{ }_{c i} \\
\beta \Delta t^{2} \mathbf{K}^{\mathrm{s}}{ }_{i c} & { }_{\mathrm{L}} \mathbf{M}^{\mathrm{s}}{ }_{i i}+\beta \Delta t^{2} \mathbf{K}^{\mathrm{s}}{ }_{i i}
\end{array}\right]\left\{\begin{array}{c}
\Delta \hat{\mathbf{a}}^{\mathrm{fs}} \\
\Delta \hat{\mathbf{a}}^{\mathrm{s}}{ }_{i}
\end{array}\right\}=\left\{\begin{array}{c}
\Delta \mathbf{g}^{\mathrm{fs}}{ }_{c} \\
\Delta \mathbf{g}^{\mathrm{s}}{ }_{i}
\end{array}\right\}}
\end{aligned}
$$

式 (21a) の係数行列は対角行列なので, 連立 1 次方程式を解くことなく, 直ちに解が求まる. ゆえに流体自由度 が非常に大きい場合, 定義 2 の式（11）を用いると計算効率が良い. 但し, クーラン数条件（12a）に加え, 拡散 数条件（12b）も課せられる. 式（7）についても同様である.

FSI に対する予測子 - 多重修正子法 (predictor-multicorrector algorithm；PMA）を用いて，時間進行させる．反 復計算ループは PMA の多重修正ループに, 式（6）はPMAの修正子に対応し, PMAの予測子はニューマーク $\beta$ 法を用いて次のように与えられる(16) :

$$
\begin{aligned}
{ }^{t+\Delta t} \mathbf{a}^{(0)} & =\mathbf{0} \\
{ }^{t+\Delta t} \mathbf{v}^{(0)} & ={ }^{t} \mathbf{v}+\Delta t(1-\gamma)^{t} \mathbf{a} \\
{ }^{t+\Delta t} \mathbf{u}^{(0)} & ={ }^{t} \mathbf{u}+\Delta t^{t} \mathbf{v}+\Delta t^{2}(1 / 2-\beta)^{t} \mathbf{a} \\
{ }^{t+\Delta t} \mathbf{p}^{(0)} & ={ }^{t} \mathbf{p}
\end{aligned}
$$

\section{3. 流路内に設置された柔軟な弁}

\section{$3 \cdot 1$ 問題設定}

図 1 に示寸ように, 流路内に柔軟な弁が設置されている. 弁の質量密度は $\rho^{\mathrm{s}}=1500 \mathrm{~kg} / \mathrm{m}^{3}$, ヤング率は $E^{\mathrm{s}}=2.3 \times 10^{6}$ $\mathrm{N} / \mathrm{m}^{2}$, ポアソン比は $v^{\mathrm{s}}=0.45$ である. また流路内を流れる流体の質量密度は $\rho^{\mathrm{f}}=956 \mathrm{~kg} / \mathrm{m}^{3}$, 粘性係数 $\mu^{\mathrm{f}}=0.145$ 
$\mathrm{kg} /(\mathrm{m} \mathrm{sec})$ ) である. 同図に示すように，流入流速の分布は放物型である．その上端での流速 $v_{\text {in }}$ は，時刻 $t<10$ の とき, $v_{\text {in }}=V_{\text {in }}(1-\cos 2 \pi f t) / 2\left(V_{\text {in }}=0.06067 \mathrm{~m} / \mathrm{sec}, f=0.05 \mathrm{~Hz}\right)$, 時刻 $t \geqq 10$ のとき, $v_{\text {in }}=V_{\text {in }}$ と与えられる.

本問題は典型的なテス卜問題のひとつであり, 最初に文献（6）において提案された. 分離型解法によっては, 連成反復が収束しにくい，または収束しないといった数值的困難さが生じることが知られている(6),(10).

\section{$3 \cdot 2$ 解析の設定}

本解析においては，等価質量行列の定義 1 の式（9）を用いる. 代表流速 $V^{\mathrm{f}}$ を流入流速の最大 $V_{\text {in }}$ で定義する. 要素の最小寸法は, $\Delta h^{\mathrm{f}}=0.025 \mathrm{~m}$ である. ゆえにクーラン数条件（12a）から, 時間刻みの下限は $\Delta t_{\text {min }}=0.412 \mathrm{sec}$

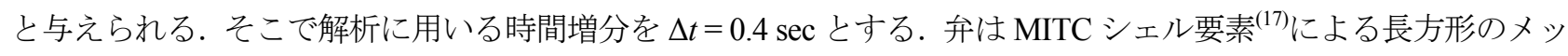
シュ（22 節点， 10 要素）を用いてモデル化されている. 流体領域は P1P1 要素 ${ }^{(18)}$ による直方体のメッシュ $(2,982$ 節点，8,400 要素）を用いてモデル化されている.ここで流体解析の安定化のために, SUPG・PSPG 法 ${ }^{(18)}$ 用い ている. 図 1 に示寸ように, 本問題は 2 次元問題なので, 紙面垂直方向 $(z$ 方向) の要素分割数を 1 とし, シェ ル構造の全節点に対して, $y$ 軸まわりの回転と $z$ 方向の並進を拘束し, 流体の全節点に対して, $\mathrm{z}$ 方向の流速を 0 とする.

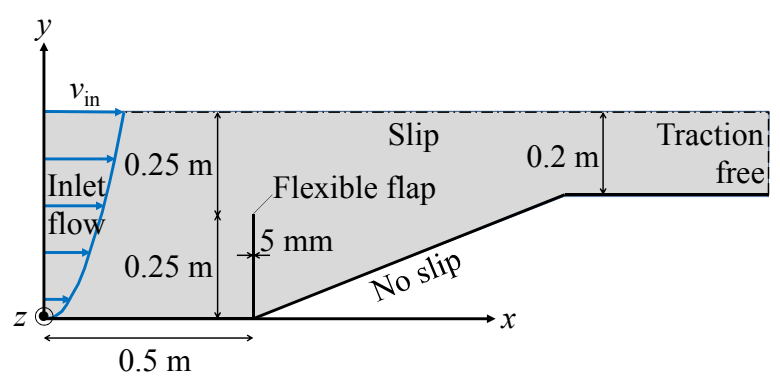

Fig. 1 Setup of the flexible flap in the channel.

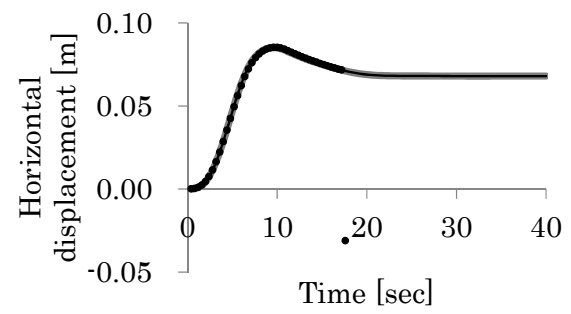

(a) time histories of $x$-displacement of the free end of the flap

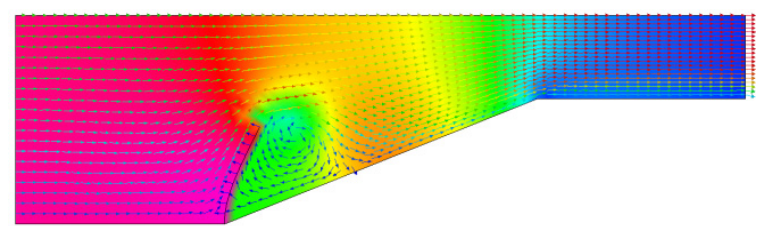

(c) velocity, pressure and deformation at time $10 \mathrm{sec}$

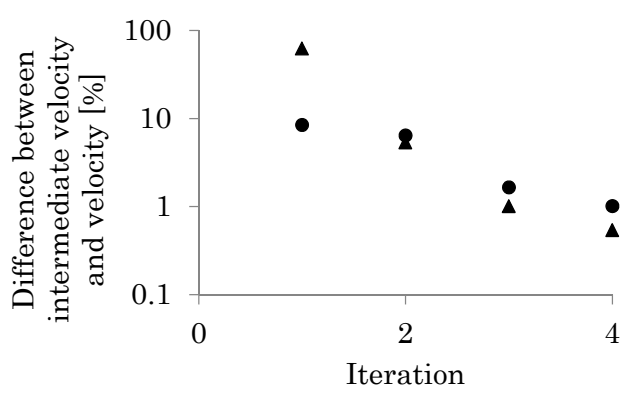

Fig. 2 Transition of the difference between the intermediate velocity and the velocity during the iterative procedure at the first time step $(\bullet)$ and the second time step $(\boldsymbol{\Delta})$.

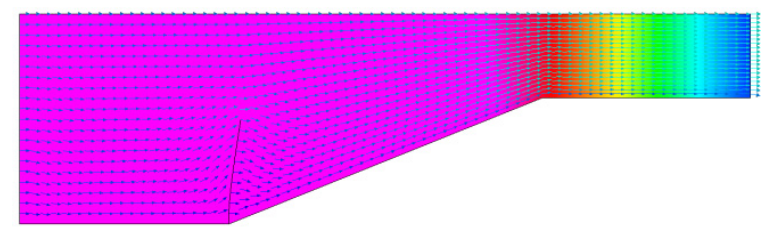

(b) velocity, pressure and deformation at time $4 \mathrm{sec}$

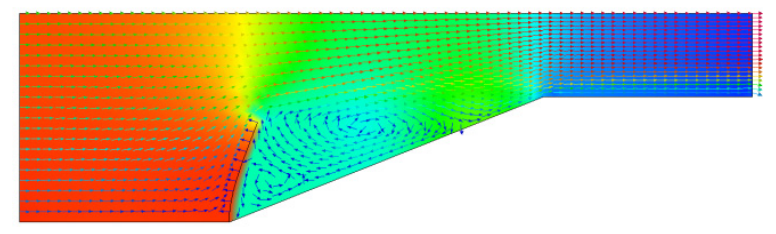

(d) f velocity, pressure and deformation at time $24 \mathrm{sec}$

Fig. 3 Time histories of the horizontal displacement of the free end of the flexible flap are shown in (a), and fluid velocity, pressure fields, and structural deformation are shown in (b), (c) and (d). In (a), the black circles indicate the result for 2 iterations, the black line indicates the result for 3 iterations and the gray line indicates the result for 4 iterations. In (b), (c) and (d), the magnitude of the pressure is expressed as a color contour from blue $(-0.5 \mathrm{~Pa})$ to magenta $(10 \mathrm{~Pa})$, and the magnitude of the velocity is expressed using a color of the vector from blue $(0 \mathrm{~m} / \mathrm{sec})$ to magenta $(0.15 \mathrm{~m} / \mathrm{sec})$. 


\section{$3 \cdot 3$ 解析結果と考察}

最初に漸近関係（20）が成り立つことを示す．このときPPE（18）を解くことによって，未知の流速場に対す る非圧縮性条件（4b）が漸近的に満たされる．中間流速と流速の差を次式で与える：

$$
\left.\sum_{i=1}^{n d o f s}\right|^{t+\Delta t} \hat{v}_{i}^{(k)}-{ }^{t+\Delta t} v_{i}^{(k)}\left|/ \sum_{i=1}^{n d o f s}\right| t+\Delta t v_{i}^{(k)} \mid
$$

ここで $n d o f s$ は自由度数, 下付き添え字 $i$ は各自由度を表す. 最初と次の時間ステップにおける中間流速と流速の 差（23）は, 図 2 のように推移した. 同図に示寸ように, 中間流速と流速の差（23）はほほ線形収束し, 3 回の 反復で約 $1 \%$ になった. 反復回数を 2,3 , または 4 回に固定した場合の弁自由端の $x$ 方向変位を図 3 (a) に示寸. 同図に示寸ように, 反復回数が 3, 4 回の結果はよく一致している. 一方, 反復回数が 2 回の場合, 平衡状態に至 る前に, 変位が突然増大し, 解析が破綻した. 以上から, 本解析の範囲では, 反復回数を 3 回とすればよいこと が判る. 反復関数を 3 回に固定した場合の流路内の様子を図 3 (b)，(c)，(d) に示寸. 図 3 に示寸反復回数 3 回 のときの解析結果は，従来の研究(6), (8)で得られた結果と良く一致している.

\section{4. 水槽内における柔軟な弾性翼の羽ばたき}

\section{$4 \cdot 1$ 問題設定}

水平な台の上に置かれた直方体の水槽をシリコン油（質量密度 $\rho^{\mathrm{f}}=0.96 \mathrm{~g} / \mathrm{cm}^{3}$, 粘性係数 $\mu^{\mathrm{f}}=0.48 \mathrm{~g} /(\mathrm{cm} \mathrm{sec})$ ) で 満たす. 造波を防ぐため, 油面上に蓋が置かれて水槽は閉じられている. 図 4 に示寸ように, 流体領域の寸法は, $x$ 方向に $75.0 \mathrm{~cm}, y$ 方向に $33.0 \mathrm{~cm}, z$ 方向に $43.8 \mathrm{~cm}$ である. ここで同図に示すように, 直交座標系を流体領域 中に固定した. 図 5 に示寸長方形翼は, 剛体の翼前縁（翼長手方向長さ $22.5 \mathrm{~cm}, 0.7 \mathrm{~cm} \times 0.7 \mathrm{~cm}$ の正方形断面), 薄く柔らかい板ばね（質量密度 $\rho^{\mathrm{s}}=0.3573 \mathrm{~g} / \mathrm{cm}^{3}$, ヤング率 $E^{\mathrm{s}}=6.561 \times 10^{9} \mathrm{~g} /\left(\mathrm{cm} \mathrm{sec}^{2}\right)$, ポアソン比 $v^{\mathrm{s}}=0.35$, 翼長 手方向長さ $22.5 \mathrm{~cm}$, 翼弦方向長さ $1.0 \mathrm{~cm}$, 翼厚 $0.03 \mathrm{~cm}$ ), および, 薄いが硬い翼面（質量密度 $\rho^{\mathrm{s}}=1.4 \mathrm{~g} / \mathrm{cm}^{3}$, ヤ ング率 $E^{\mathrm{s}}=2.45 \times 10^{10} \mathrm{~g} /\left(\mathrm{cm} \mathrm{sec}^{2}\right)$, ポアソン比 $v^{\mathrm{s}}=0.4$, 翼長手方向長さ $22.5 \mathrm{~cm}$, 翼弦方向長さ $2.6 \mathrm{~cm}$, 翼厚 $\left.0.1 \mathrm{~cm}\right)$ から構成される.ここで板ばねの曲げ岡性は $0.00399 \mathrm{~N} \mathrm{~m}^{2}$ であり, 翼面の曲げ岡性 $0.551 \mathrm{~N} \mathrm{~m}^{2}$ の約 138 倍である. 翼の基部を座標系の原点に置く．安静時に翼弦は鉛直の向きにある．ストローク軸は $y$ 軸と同一である．ストロ 一ク面は $y=0$ の面内にあり, $z$ 軸に関して対称である. ストローク角 $\Phi$ は $123^{\circ}$ である. ストローク角変位 $\varphi$ は, 翼前縁と $z$ 軸のなす角であり, $y$ 軸周りに反時計回りを正とする。 $\varphi$ は，初め- $\Phi / 2$ である. 図 6 に示寸関数を用い て, $\varphi$ の時間変化を与える. 羽ばたき周波数 $f_{\varphi}$ は $0.521 \mathrm{~Hz}$ である. 翼が羽ばたくと, 流体力が翼面に作用して, 板ばねが曲がる.この変形の程度を, 図 5 に示すピッチ角 $\theta$ により評価する.ここで $\theta$ は翼弦と鉛直方向のなす 角であり，翼の基部から先端に向から翼長手軸周りに反時計回りを正とする.

分離型解法をこの問題に適用した場合, 流体と構造の質量密度が同程度であること ${ }^{(14)}$, 薄い翼が习习习゙゙たくこと

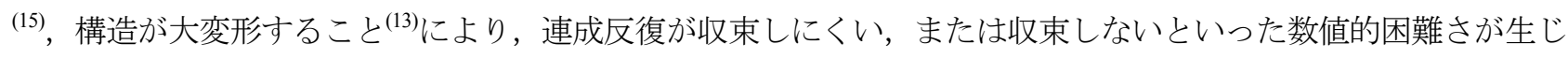
る可能性がある.

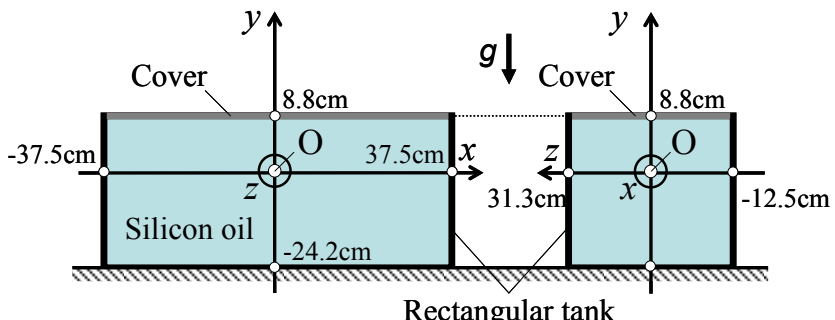

Rectangular tank

Fig. 4 The fluid domain. The rectangular tank is filled with oil and closed using the cover to prevent the wave generation.

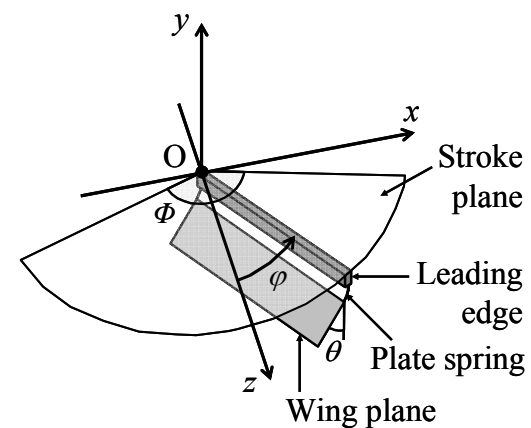

Fig. 5 The rectangular wing. It consists of the rigid leading edge, the thin flexible plate spring and the thin stiff wing plane. 


\section{$4 \cdot 2$ 解析の設定}

本解析においては，流体解析規模がかなり大きくなるので，流体の非連成自由度に関して，連立 1 次方程式を 解く必要が無くなる等価質量行列の定義 2 の式（11）を用いる. 代表流速 $V^{\mathfrak{f}}$ をストローク速度の最大で定義する と, $V^{\mathrm{f}}=L_{\mathrm{w}}(d \varphi / d t)_{\max }=1.01 \mathrm{~m} / \mathrm{sec}\left(L_{\mathrm{w}}\right.$ : 翼長 $0.225 \mathrm{~m},(d \varphi / d t)_{\max }$ : ストローク角速度の最大 $\left.4.47 \mathrm{rad} / \mathrm{sec}\right)$ となる. また要素の最小寸法 $\Delta h^{\mathrm{f}}=0.00333 \mathrm{~m}$ である.このとき時間刻みの制約は, クーラン数条件 (12a) から $0.00332 \mathrm{sec}$, 拡散数条件 (12b) から $0.111 \mathrm{sec}$ と与えられるので，時間刻みの下限は $\Delta t_{\min }=0.00332 \mathrm{sec}$ となる．そこで解析に 用いる最小の時間増分 $\Delta t$ を羽ばたき周期 $T_{\varphi}=1 / f_{\varphi}$ の $1 / 5000$ とする. これは $\Delta t_{\min }$ の約 $1 / 10$ である. 全解析時間を $T_{\varphi}$ の 10 倍とする. 図 8 に解析モデル翼が示されている.ソリッドの角柱として表されている翼前縁は, 移動境

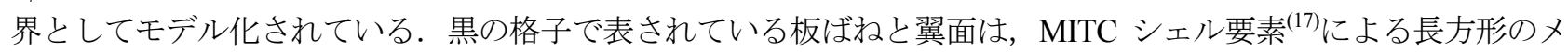
ッシュ（121 節点， 100 要素）を用いてモデル化されている. その上端は前縁に固定されている. 流体領域は, P1P1 要素 ${ }^{(18)}$ による直方体のメッシュ（46,911 節点，254,352 要素）を用いてモデル化されている. ここで流体解 析の安定化のために, SUPG・PSPG 法(18)を用いている．流体領域の全ての境界に滑り無し条件が課される. 文献

（1）の実験装置に，4・1 節の問題設定を適用して，本計算結果と比較するための実験結果を得る.

\section{$4 \cdot 3$ 解析結果と考察}

3 ・3 節と同様に，最初に漸近関係（20）が成り立つことを示す．中間流速と流速の差を式（23）で与える. 時 間増分 $\Delta t$ を羽ばたき周期 $T_{\varphi}=1 / f_{\varphi}$ の $1 / 5,000,1 / 10,000,1 / 50,000$ としたとき，最初の時間ステップにおける中間 流速と流速の差（23）は，図７のように推移した，同図に示すように，中間流速と流速の差（23）はほぼ線形収 束し, 5 回の反復で約 $1 \%$ なった. 本解析の範囲では, 反復計算の収束性や計算結果に対する時間増分の影響が 小さいので, 以後の解析においては, $\Delta t=T_{\varphi} / 5,000$, 反復回数を一定の 5 回として, 全体の解析を行った.

6 サイクルから 7 サイクルまでの間の翼の羽ばたきと翼の周囲の流速場を図 8 に示す.ここで同図において, 翼長 $60 \%$ の位置の翼弦が，羽ばたき並進（flapping translation）する円筒面上において，流速場を表示した．円筒

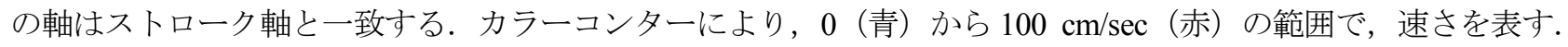
翼前縁はソリッドの角柱により表されている. 板ばねと翼面に対応するシェル構造は, 黒の格子により表されて いる．翼は 6.5 サイクルまで左から右に羽ばたき（図 8 (a)，（b)），6.5 サイクル以降は右から左に羽ばたく（図 8 (c), (d)). 同図に示寸ように, 翼は大きく変形し, ピッチ角 $\theta$ の最大は約 $50^{\circ}$ に達した．揚力の時刻歴を図 9 に示す．同図には，6から 7 サイクルまでの実験結果（灰色の線で表す）も示されている.ここで翼面に作用す る流体力の総和の鉛直方向成分により，揚力を与える．同図に示すように，1 サイクル目からほぼ周期的定常状 態となった. 十分時間の経過した 6 から 7 サイクルにおいて, 本計算結果は対応する実験結果とよく一致した. ゆえに本解法は長周期に渡って，安定に精度良く解析を行うことができる。

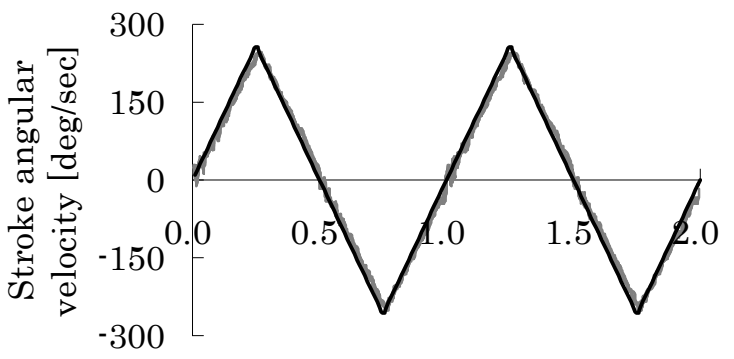

Time [cycle]

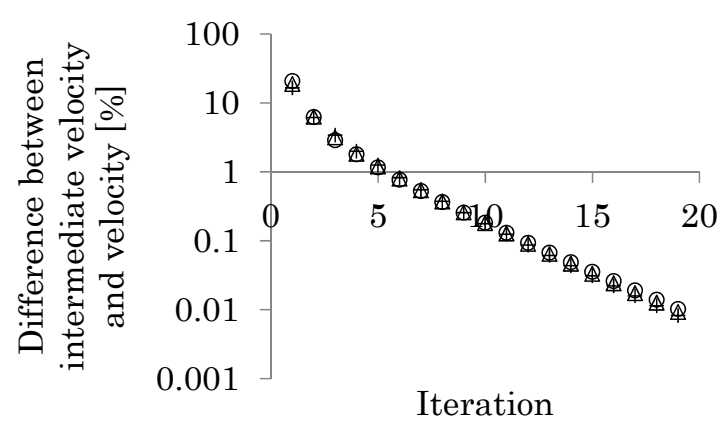

Fig. 7 Transition of the difference between the intermediate velocity and the velocity during the iterative procedure at the first time step (+: $\Delta t=T_{\varphi} / 5,000, \Delta: \Delta t=T_{\varphi} / 10,000, \circ: \Delta t=$ $\left.T_{\varphi} / 50,000\right)$. 


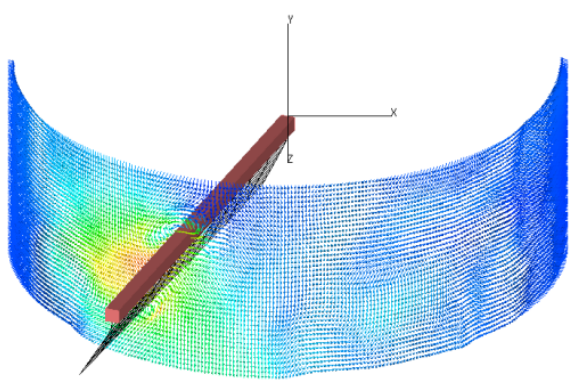

(a) 6.2 cycles

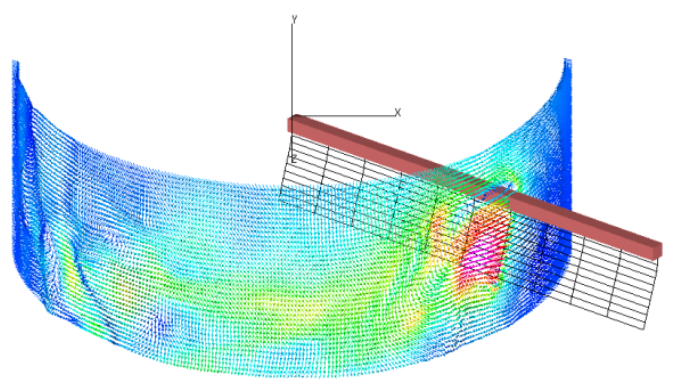

(b) 6.4 cycles

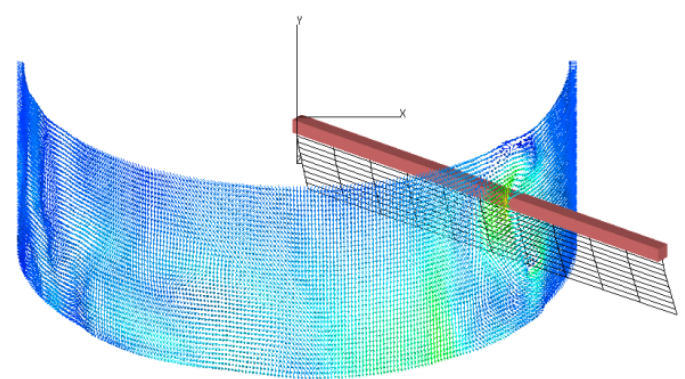

(c) 6.6 cycles

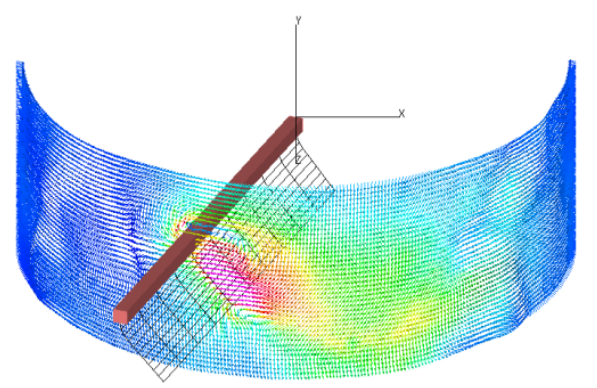

(d) 6.8 cycles

Fig. 8 The fluid velocity field on a cylindrical plane during the sixth cycle. The wing flapped from left to right in the left column (a) and (b) while it flapped from right to left in the right column (c) and (d).

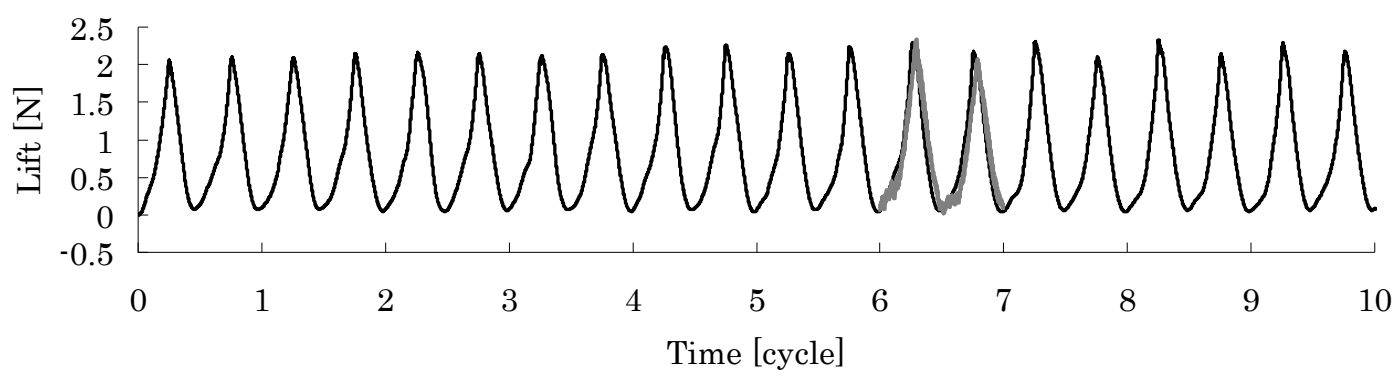

Fig. 9 Time histories of the lift from the present computation (black line). The experimental results during the 6 th cycle are also provided (gray lines).

\section{5. 結言}

本研究では, 非圧縮性流体と弾性構造の連成に対する整合プロジェクション解法を提案した. 非線形方程式の 反復解法の枠組みの中で，一体型方程式の平衡方程式と PPE への分割を，中間状態変数を利用して行った．この 定式化により, 一体型解法との整合性を保ちつつ, 方程式の自由度を低減することができる. 反復計算において, 中間速度が速度と漸近的に一致し，PPE を解くことにより，漸近的に非圧縮性条件が満たされることを示した。 本研究で用いた $2 つ の$ 数值計算例では, 分離型解法における連成反復の収束性が悪化し, 計算が破綻する可能性 がある．本プロジェクション解法により，それらの問題を安定かつ精度良く解析することができた. 


\section{文献}

(1) Ishihara, D., Yamashita, Y., Horie, T., Yoshida, S., Niho, T., "Passive maintenance of high angle of attack and its lift generation during flapping translation in crane fly wing”, The Journal of Experimental Biology, Vol. 212, (2009), pp. 3882-3891.

(2) Guermond, J.L., Minev, P., Shen, J., “An overview of projection methods for incompressible flows", Computer Methods in Applied Mechanics and Engineering, Vol. 195, (2006), pp. 6011-6045.

(3) Codina, R., "Pressure stability in fractional step finite element methods for incompressible flows", Journal of Computational Physics, Vol. 170, (2001), pp. 112-140.

(4) Fernandez, M.A., Gerbeau, J.-F., Grandmont, C., "A projection semi-implicit scheme for the coupling of an elastic structure with an incompressible fluid”, International Journal for Numerical Methods in Engineering, (2007), Vol. 69, pp. $794-821$.

(5) Badia, S., Quaini, A., Quarteroni, A., "Splitting methods based on algebraic factorization for fluid-structure interaction", SIAM Journal on Scientific Computing, Vol. 30, No. 4 (2008), pp. 1778-1805.

(6) Neumann, M, Tiyyagura, S.R., Wall, W.A., Ramm, E., "Robustness and efficiency aspects for computational fluid structure interaction", Computational Science and High Performance Computing II, Vol. 91 (2006), pp.99-114.

(7) Ishihara, D., Yoshimura, S., "A monolithic approach for interaction of incompressible viscous fluid and an elastic body based on fluid pressure Poisson equation", International Journal for Numerical Methods in Engineering, Vol. 64, (2005), pp. 167-203.

(8) Idelsohn, S.R., Del Pin, F., Rossi, R., Onate, E., "Fluid-structure interaction problems with strong added-mass effect", International Journal for Numerical Methods in Engineering, Vol. 80, (2009), pp. 1261-1294.

(9) Heil, M., "An efficient solver for the fully coupled solution of large-displacement fluid-structure interaction problems", Computer Methods in Applied Mechanics and Engineering, Vol. 193, (2004), pp. 1-23.

(10) Minami, S., Yoshimura, S., "Performance evaluation of nonlinear algorithms with line-search for partitioned coupling techniques for fluid - structure interactions", International Journal for Numerical Methods in Fluids, Vol. 64, (2010), pp. 1129-1147.

(11) Matsumoto, J., Kawahara, M., "Shape identification for fluid-structure interaction problem using improved bubble element", International Journal of Computational Fluid Dynamics, Vol. 15, (2001), pp. 33-45.

(12) Matsumoto, J., Suzuki, T., Tezuka, A., "Large-scale fluid-structure strong interaction analysis using stabilized bubble function finite element method", Proceedings of the Congress on Computational Engineering and Science, Vol. 8, (2003), pp. 609-612 (in Japanese).

(13) Dettmer, W., Peric, D., “A computational framework for fluid-structure interaction: Finite element formulation and applications", Computer Methods in Applied Mechanics and Engineering, Vol. 195, (2006), pp. 5754-5779.

(14) Causin, P., Gerbeau, J.F., Nobile, F., “Added-mass effect in the design of partitioned algorithms for fluid-structure problems", Computer Methods in Applied Mechanics and Engineering, Vol. 194, (2005), pp. 4506-4527.

(15) Yamada, T., Yoshimura, S., "Line search partitioned approach for fluid-structure interaction analysis of flapping wing", Computer Modeling in Engineering and Sciences, Vol. 24, No. 1 (2008), pp. 51-60.

(16) Zhang, Q., Hisada, T., “Analysis of fluid-structure interaction problems with structural buckling and large domain changes by ALE finite element methods", Computer Methods in Applied Mechanics and Engineering, Vol. 190, (2001), pp. 6341-6357.

(17) Noguchi, H., Hisada, T., "Sensitivity analysis in post-buckling problems of shell structures”, Computers and Structures, Vol. 47, (1993), pp. 699-710.

(18) Tedzduyar, T.E., Mittal, S., Ray, S.E., Shih, R., "Incompressible flow computations with stabilized bilinear and linear equal-order-interpolation velocity-pressure elements", Computer Methods in Applied Mechanics and Engineering, Vol. 95, (1992), pp. 221-242.

(19) Hughes, T.J.R., Liu W.K., Zimmerman T.K., "Lagrangian-Eulerian finite element formulation for incompressible viscous flows", Computer Methods in Applied Mechanics and Engineering, Vol. 29 (1981), pp. 329-349. 